\title{
Comprehensive laparoscopic approach to pediatric varicocele based on preoperative color Doppler ultrasound assessment
}

\author{
M. Cimador - M. R. Di Pace - M. Castagnetti • \\ M. Sergio $\cdot$ P. Catalano $\cdot$ E. De Grazia
}

(C) Springer Science+Business Media, LLC 2007

\begin{abstract}
Background This study aimed to assess whether laparoscopic treatment for any kind of varicocele is possible after preoperative identification of refluxing veins by color Doppler ultrasound (CDUS).

Methods At the authors' institution, 98 patients with a median age of 11.3 years (range, 7.1-16 years) were evaluated for a left varicocele. Preoperatively, all the patients underwent ultrasound scan assessment of testicular volume and CDUS to rule out reflux into the internal spermatic vein (ISV), deferential vein, or cremasteric vein. In all the patients, laparoscopic division of the spermatic artery and veins was performed as close as possible to the internal inguinal ring. The other vessels were coagulated and divided if shown to be refluxing on CDUS.

Results Color Doppler ultrasound showed reflux only in the ISV in 87 cases (88.7\%), but in both the ISV and the deferential in the remaining 11 cases (11.2\%). During a median follow-up period of 18 months (range, 6-49 months), none of the authors' patients experienced varicocele recurrence either clinically or according to CDUS scanning. The median left testicular volume increased significantly postoperatively.

Conclusion The proposed technique based on laparoscopic interruption of the ISV and testicular artery very close to the internal inguinal ring, meticulous CDUS assessment to rule out reflux in the deferential vein, and
\end{abstract}

M. Cimador $(\bowtie) \cdot$ M. R. Di Pace · M. Castagnetti ·

M. Sergio · P. Catalano · E. De Grazia

Department of Paediatric Surgery, University of Palermo,

Dipartimento Universitario Materno Infantile, Via Cardinale

Rampolla 1, 90142 Palermo, Italy Palermo, Italy

e-mail: mcimador@unipa.it coagulation of refluxing deferential veins allows successful laparoscopic treatment of most varicoceles.

Keywords Color Doppler ultrasound · Laparoscopy · Recurrence · Varicocele

Successful surgical treatment of a varicocele requires the interruption of every refluxing vein draining the testicle. The most commonly refluxing vein is the internal spermatic vein (ISV) [1]. The ISV can be interrupted using several techniques including classic surgical repair via a subinguinal, inguinal, or high retroperitoneal approach; minimally invasive surgery; or percutaneous scleroembolization $[2,3]$. Any technique relying on interruption of the ISV alone, however, may involve varicocele recurrence or persistence whenever veins draining the testicle other than the ISV are refluxing as well $[1,4,5]$.

In our early experience, to interrupt all the possible refluxing systems, we performed varicocelectomy via a microsurgical subinguinal ligation of all the dilated veins detected at surgery [6]. Subsequently, the development of accurate techniques for color Doppler ultrasound (CDUS) allowed us to perform preoperatively an accurate and comprehensive assessment of all the major venous systems draining the testicles [7]. We therefore started to restrict the subinguinal approach to varicoceles with reflux detected in multiple veins and to treat those due to reflux only into the ISV by laparoscopic high ligation according to Palomo.

The current study aimed to test the hypothesis that successful laparoscopic treatment for any kind of varicocele can be achieved by selective laparoscopic interruption of all the veins detected by preoperative CDUS to be refluxing. 
Fig. 1 Laparoscopic view of the right and left internal inguinal rings (IIR) in the same patient with a left varicocele. On the left, both the internal spermatic vein (ISV) and the deferential vein are dilated
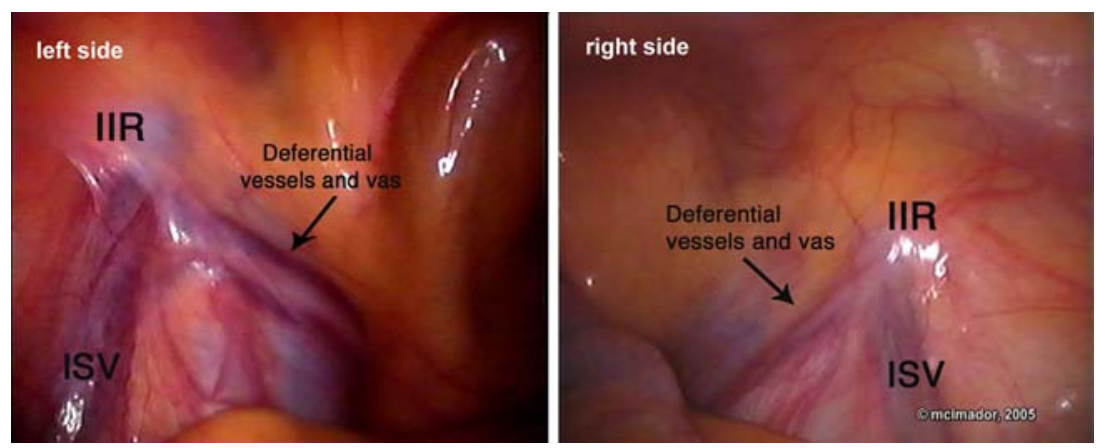

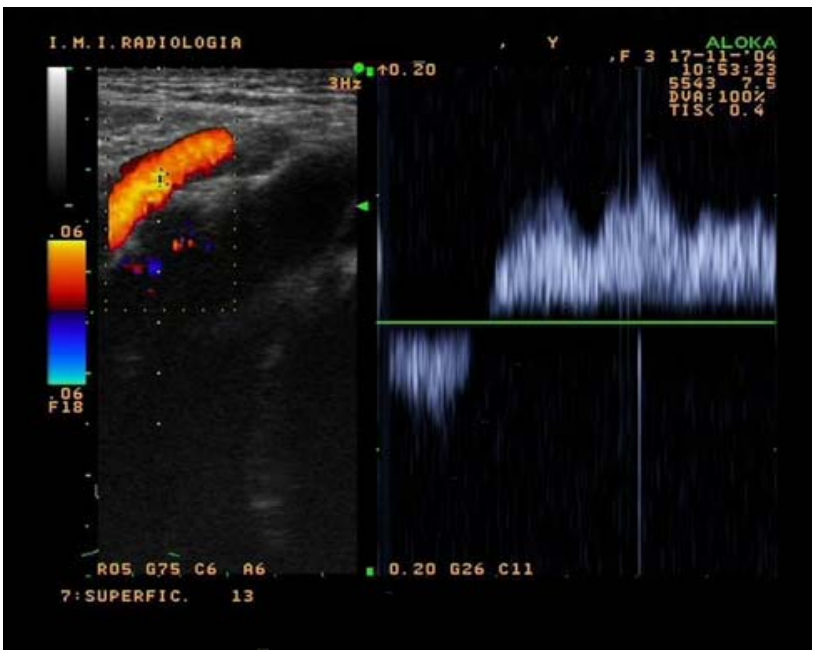

Fig. 2 Deferential reflux on color Doppler ultrasound and related spectral analysis

\section{Materials and methods}

From January 2001 to October 2005, 98 patients with a median age of 11.3 years (range, 7.1-16 years) were evaluated at our institution for the presence of a left varicocele. All varicoceles were graded clinically according to Dubin and Amelar [8] by scrotal examination in the supine and upright positions. Patients underwent surgical treatment if they presented with a grade 3 varicocele or a grade 2 varicocele associated with pain, scrotal discomfort, or hypotrophy of the left testicle.

Preoperatively, all the patients underwent ultrasound scan assessment performed using a linear multifrequency 7- to $13-\mathrm{MHz}$ transducer connected to an Aloka Prosound SSV500, (Tokyo, Japan). For CDUS pulse repetition, the frequency was set at $1.5 \mathrm{kHz}$. Using ultrasound, testicular volume was calculated in milliliters with the formula $\mathrm{V}=$ $0.52 \times$ length $\times$ width $\times$ thickness of the testicular ellipsoid.

We performed CDUS as previously described [7]. The venous reflux was assessed with the patients at rest and during the Valsalva maneuver in both the upright and supine positions. Both the inguinal canal and the left iliac fossa were examined for a possible retrograde refluxing blood flow in the ISV, deferential veins, and cremasteric veins. The number and the transverse diameter of dilated veins were measured. The deferential vein normally is not visible on CDUS in healthy boys both at rest and after the Valsalva maneuver. When dilated, it can be visualized in the left iliac fossa running over the external iliac vein and artery. The former can be used as a landmark.

Boys presenting on CDUS with reflux in the ISV were treated via a transperitoneal Palomo procedure. A 5-mm, $0^{\circ}$ umbilical telescope and two operating ports were placed. A peritoneal window was created, followed by careful dissection of the ISV and spermatic artery off the retroperitoneal fat. During this step, care was taken to avoid any injury to the fat, thus averting as much as possible any injury to the lymphatic vessels lying on it. Laparoscopic division of the spermatic artery and veins was performed.

Patients presenting at surgery with dilated deferential veins (Fig. 1) proved by preoperative CDUS to be refluxing (Fig. 2) were treated by a Palomo procedure, as described earlier but combined with coagulation and division of deferential veins as follows. The retroperitoneal window was widened toward the internal inguinal ring. The deferential veins running as satellites of the vas were gently dissected off the deferential artery (Fig. 3), which was spared because it could remain the almost unique blood supply of the testicle. The deferential vein then was coagulated with bipolar diathermy and divided.

Sometimes it is easier to approach the deferential vein in the deep pelvis just beneath the iliac vessels. In these cases, a second retroperitoneal window is required.

As follow-up assessment, clinical and CDUS assessments were performed $1,3,6$, and 12 months postoperatively. Recurrence or persistence of the varicocele, the presence of a hydrocele, and testicular volume were assessed.

Data are reported as median and range. The Wilcoxon test was used to compare the pre- and postoperative volumes of the affected left testicle. 


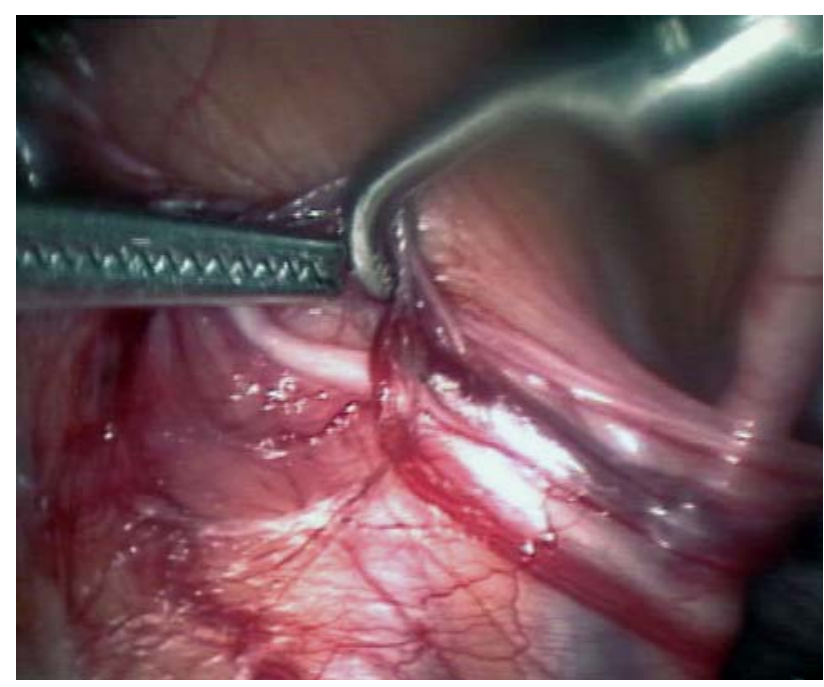

Fig. 3 Deferential veins dissected off the vas

\section{Results}

According to the findings, 71 boys (72.4\%) had a grade 3 and $26(26.5 \%)$ a grade 2 varicocele. A total of 12 boys with a grade 2 varicocele reported left scrotal discomfort or pain, whereas the remaining boys had testicular asymmetry.

In 87 cases $(88.7 \%)$, CDUS showed reflux only in the ISV, whereas a reflux in both the ISV and the deferential vein was observed in the remaining 11 cases (11.2\%). No varicocele was caused by an isolated deferential reflux, and no reflux in the cremasteric vein was observed.

Therefore, a laporoscopic Palomo procedure was performed for the former 87 boys, whereas coagulation and section of the deferential vein was added for the remaining 11 boys. In two cases, we approached the deferential vein in the deep pelvis because of a more evident dilation of the vein.

After a median follow up period of 18 months (range, 649 months), three cases $(4.2 \%)$ of postoperative hydrocele were observed, all of which resolved spontaneously. None of our patients experienced varicocele recurrence either clinically or according to CDUS scanning. No case of testicular atrophy was observed. Median left testicular volume increased significantly after surgery $(p=0.025)$ in the patients presenting with hypotrophy of the left testicle.

\section{Discussion}

Approximately $90 \%$ of varicoceles are left-sided [8], and about $75 \%$ of these are attributable to a reflux in the ISV only [1]. This kind of varicocele can be addressed successfully by several techniques including open surgical ligation via a subinguinal, inguinal, or retroperitoneal approach; minimally invasive procedures; or radiologic embolization $[2,3]$. The only possible cause for recurrence in this scenario is the presence of collaterals bypassing the site of ISV interruption [1, 4, 9]. These collaterals also can be nondilated at the time of surgery and are more commonly missed if the internal spermatic artery is spared [10]. Accordingly, we have never spared this artery and, consistent with previous data [10], this has never caused any testicular atrophy.

Venographic studies have shown the existence of various collaterals of the ISV including vessels arising from an independent second ostium in the renal vein or from retroperitoneal vessels [9]. In our opinion, to avoid missing any such collateral, the key is to interrupt the veins as close as possible to the internal inguinal ring. Although this is quite in contrast with the generally accepted principle that the higher the ligature the smaller the risk of missing refluxing bypassing collaterals, it is warranted by the fact that all the veins necessarily converge at this level. The optical magnification of the laparoscope and the optimal anatomic view through the peritoneum usually allow for precise identification of these vessels, a possibility peculiar to laparoscopy and, in our opinion, quite different from open surgery and retroperitoneoscopy.

Venographic studies also have shown that a proportion of cases may additionally involve refluxing pelvic collaterals [1, 4, 5]. This was first acknowledged by Coolsaet [1], who classified varicoceles into three types: type 1 due to a reflux into the ISV only, type 2 due to a reflux into the iliac venous system (cremasteric or deferential veins), and type 3 due to a reflux into both venous systems. Further studies have challenged this classification. Franco et al. [11] questioned the existence of a cremasteric reflux, and cases of recurrence or persistence due to reflux in veins not considered in the Coolsaet classification also have been described $[4,5]$.

For years, pre- or intraoperative venography has represented the standard for the search to find collaterals. However, other methods also have been devised. Campobasso [5] suggested the intraoperative use of blue venography. Nyirady et al. [12] described an ingenious trick consisting of a laparoscopic search for collaterals that dilate when the blood is squeezed out the testicle by manual compression after interruption of the ISV.

For our patients, we relied instead on CDUS assessment of the veins draining the testicle. Our method potentially allows a preoperative noninvasive identification of the refluxing veins, differentiating those actually refluxing from those dilated due to overflow and grading the reflux in an objective manner on the basis of duration, velocity, and refluxing volume [7, 13, 14]. For our patients, CDUS showed that the ISV was always refluxing. In $88.7 \%$ of cases, it was the only refluxing vein, whereas in $11.3 \%$ of 
cases, a deferential reflux also was associated. In keeping with Franco et al. [11], none of our patients presented with a cremasteric reflux.

The ultimate role of pelvic refluxing collaterals in causing varicocele persistence or recurrence remains controversial. Perhaps a controlled trial alone may properly address this issue. However, indirect evidence suggests that in a few cases, varicocele persistence or recurrence can be caused by such refluxing collaterals $[4,15]$.

Consistently, to date, we have considered it mandatory to interrupt any refluxing veins. For this purpose, we have initially adopted the microsurgical subinguinal ligation of dilated veins, proposed as the most flexible procedure [2]. Indeed, it is reportedly the technique with the lowest recurrence rate [16], and we previously experienced a recurrence rate as low as $2.8 \%$ [6]. Of course, success requires a meticulous search for any dilated and potentially refluxing vein.

In the attempt to achieve the same goal laparoscopically, Dudai et al. [17] suggested systematically interrupting both the ISV and the inferior epigastric vessels. This procedure, however, causes unnecessary division of many nonrefluxing veins and can address only a possible cremasteric reflux, whereas CDUS has allowed us to identify the refluxing venous systems preoperatively and hence to select the surgical treatment accordingly.

On the basis of CDUS findings, in a previous study, we proposed to restrict open microsurgical subinguinal varicocelectomy to cases with reflux in multiple systems and to treat varicoceles due to a reflux only in the ISV by a laparoscopic Palomo procedure. Doing so, we did not observe any recurrence in 42 treated cases [7].

In this study, we tested the possibility of extending the laparoscopic treatment also to patients with multiple refluxing venous systems. Indeed, facing a refluxing deferential vein, we managed to dissect, coagulate, and divide this vein laparoscopically near the vas. Extreme care must be paid during dissection to avoid injures to the surrounding vessels, vas, and deferential artery, which in some cases could become the almost unique blood supply to the testicle. To date, however, we have not experienced any case of testicular atrophy. Interruption of the epigastric vessels could be added to the procedure for treatment of a cremasteric reflux if present. In the current series of 98 cases, there was no recurrence.

The described technique can clearly address only varicoceles due to reflux in the ISV, deferential, or cremasteric veins. Cases with other types of pelvic refluxing veins are missed. Nevertheless, the incidence of these vessels is very low $[4,5]$, and their actual role in causing a clinically relevant varicocele is questionable.

The proposed procedure also showed a very low rate of hydroceles $(4.2 \%)$ for a nonartery-sparing technique [18].
All hydroceles resolved spontaneously. In our previous experience with subinguinal varicocelectomy, we instead were forced to perform vaginal eversion to minimize the incidence of such complication. Oswald et al. [19] suggested the use of a specific dye to highlight the lymphatic vessels. However, we believe that to spare the lymphatic vessels, it is sufficient to avoid any damage to the retroperitoneal fat on which these vessels lie.

In conclusion, our diagnostic approach is a rigorous standard for identifying all the venous systems concurring with the varicocele. Our technique with laparoscopic interruption of the ISV and testicular artery very close to the internal inguinal ring and coagulation of deferential veins when proved by CDUS to be refluxing may allow successful treatment for most varicoceles.

\section{References}

1. Coolsaet BL (1980) The varicocele syndrome: venography determining the optimal level for surgical management. J Urol 124:833-839

2. Skoog SJ, Roberts KP, Goldstein M, Pryor JL (1996) The adolescent varicocele: what's new with an old problem in young patients? Pediatrics 100:112-122

3. Diamond DA (2003) Adolescent varicocele: emerging understanding. BJU Int 92:48-51

4. Niedzielski J, Paduch DA (2001) Recurrence of varicocele after high retroperitoneal repair: implications of intraoperative venography. J Urol 165:927-929

5. Campobasso P (1997) Blue venography in adolescent varicocelectomy: a modified surgical approach. J Pediatr Surg 32:12981301

6. Cimador M, Castagnetti M, Ajovalasit V, Libri M, Bertozzi M, De Grazia E (2003) Subinguinal interruption of dilated veins in adolescent varicocele: should it be considered a gold standard technique? Minerva Pediatr 55:599-605

7. Cimador M, Di Pace MR, Peritore M, Sergio M, Castagnetti M, De Grazia E (2006) The role of color Doppler ultrasound in determining the proper surgical approach to the management of varicocele in children and adolescents. BJU Int 97:1291-1297

8. Dubin L, Amelar RD (1970) Varicocele size and results of varicocelectomy in selected subfertile men with varicocele. Fertil Steril 21:606-609

9. Lenz M, Hof N, Kersting-Sommerhoff B, Bautz W (1996) Anatomic variants of the spermatic vein: importance for percutaneous sclerotherapy of idiopatic varicocele. Radiology 198:425-431

10. Kass EJ, Marcol B (1992) Results of varicocele surgery in adolescents: a comparison of techniques. J Urol 148:694-697

11. Franco G, Iori F, de Dominicis C, Dal Forno S, Mander A, Laurenti C (1999) Challenging the role of cremasteric reflux in the pathogenesis of varicocele using a new venographic approach. J Urol 161:117-121

12. Nyirady P, Kiss A, Pirot L, Sarkozy S, Bognar Z, Csontai A, Merksz M (2002) Evaluation of 100 laparoscopic varicocele operations with preservation of testicular artery and ligation of collateral vein in children and adolescent. Eur Urol 42:594-597

13. Niedzielski J, Paduch D, Raczynsji P (1997) Assessment of adolescent varicocele. Pediatr Surg Int 12:410-413

14. Nagar H, Mabjeesh NJ (2000) Decision making in pediatric varicocele surgery: use of color Doppler ultrasound. Pediatr Surg Int 15:75-76 
15. Esposito C, Monguzzi GL, Gonzales-Sabin MA, Rubino R, Montinaro L, Papparella A, Amici G (2000) Laparoscopic treatment of pediatric varicocele: a multicenter study of the Italian society of video surgery in infancy. J Urol 163:1944-1946

16. Goldstein M, Gilbert BR, Dicker AP, Dwosh J, Gnecco C (1992) Microsurgical inguinal varicocelectomy with delivery of the testis: an artery and lymphatic-sparing technique. J Urol 148: 1808-1811

17. Dudai M, Sayfan J, Mesholam J, Sperber Y (1995) Laparoscopic simultaneous ligation of internal and external spermatic veins for varicocele. J Urol 153:704-705
18. Esposito C, Valla JS, Najmaldin A, Shier F, Mattioli G, Savanelli A, Castagnetti M, McKinley G, Stayaert H, Settimi A, Jasonni V, Guys JM (2004) Incidence and management of hydrocele following varicocele surgery in children. J Urol 171:1271-1273

19. Oswald J, Korner I, Riccabona M (2001) The use of isosulphan blue to identify lymphatic vessels in high retroperitoneal ligation of adolescent varicocele: avoiding postoperative hydrocele. BJU Int 87:502-504 